DEHOUVE Danièle, Essai sur la royauté sacrée en

République mexicaine, CNRS Éditions, coll. « CNRS Anthropologie », Paris, 2006, 142 p., bibl., ill., photos coul.

\title{
Claude-François Baudez
}

\section{(2) OpenEdition}

\section{Journals}

Édition électronique

URL : https://journals.openedition.org/jsa/3219

DOI : 10.4000/jsa.3219

ISSN : 1957-7842

Éditeur

Société des américanistes

Édition imprimée

Date de publication : 1 juin 2006

ISSN : 0037-9174

Référence électronique

Claude-François Baudez, «DEHouve Danièle, Essai sur la royauté sacrée en République mexicaine, CNRS Éditions, coll. "CNRS Anthropologie », Paris, 2006, 142 p., bibl., ill., photos coul. », Journal de la Société des américanistes [En ligne], 92-1 et 2 | 2006, mis en ligne le 06 avril 2007, consulté le 04 septembre 2022. URL : http://journals.openedition.org/jsa/3219 ; DOI : https://doi.org/10.4000/jsa.3219

Ce document a été généré automatiquement le 4 septembre 2022

Tous droits réservés 


\title{
DEHOUVE Danièle, Essai sur la royauté sacrée en République mexicaine, CNRS Éditions, coll. «CNRS Anthropologie ", Paris, 2006, 142 p., bibl., ill., photos coul.
}

\author{
Claude-François Baudez
}

1 Entre 1950 et 1990, le « système des charges » était le modèle le plus souvent invoqué par les ethnologues pour rendre compte de l'organisation politique et rituelle des communautés indiennes du Mexique et du Guatemala. Dans ce modèle, les postes publics détenus au sein de chaque communauté sont consacrés, les uns à l'administration municipale, les autres à la célébration des rites et des fêtes religieuses. Ces postes ou charges sont occupés, à tour de rôle et selon une rotation annuelle, par des hommes de la communauté suivant une échelle hiérarchique de coût et de prestige: les hommes gravissent cette échelle en faisant alterner charge civile et charge religieuse. Si tous les hommes sont appelés à remplir ces charges, seuls quelques-uns parviennent en fin de vie au sommet de la hiérarchie. Ainsi le système est responsable de la stratification sociale interne de la communauté. Ce modèle séduisant s'est révélé non seulement fictif, mais aussi nocif, dans la mesure où il dissocie le politique du religieux. Il s'avère qu'en fait les charges ne sont pas remplies par des individus, mais par des groupes, et qu'elles sont toutes considérées comme sacrées. Les enquêtes ethnologiques ont fini par ne s'intéresser qu'à la hiérarchie et aux rapports entre richesse et prestige, pouvoir et statut, ou au seul domaine symbolique, ce qui explique la mode du chamanisme, "mise à toutes les sauces » mésoaméricaines. Face à ces dérives, Danièle Dehouve propose de substituer au système des charges le modèle de la royauté sacrée. Au centre de ce système, il y a toujours un personnage "responsable» de la prospérité de son peuple et chargé du culte; grâce au rituel, il est le "sacrifiant " qui s'identifie à la fois à l'univers et à la société tout entière. L'organisation sociale se construit autour de ce personnage rituel universel, investi d'une série de fonctions : il est juge, guerrier et prêtre. Ces différentes 
fonctions royales peuvent être remplies par lui seul ou distribuées entre plusieurs personnes. On assiste ensuite au "déploiement d'un éventail de dignitaires et de spécialistes, chacun d'entre eux ayant à cœur de constituer autour de lui une réplique du noyau central constitué autour, et au plus près, de la personne royale » (p. 31).

Le système de royauté sacrée s'applique d'abord à la société aztèque précolombienne. Le souverain, cœur de la collectivité, cumule toutes les fonctions et les délègue à ses représentants. Il est à la fois victime et garant de la prospérité, coupable et juge, pénitent et sacrifiant. Toutes les cérémonies suivent le modèle de l'intronisation royale qui comprend deux phases : l'expiatoire avec le jeûne, l'abstinence, et un cortège de diverses macérations, parmi lesquelles l'autosacrifice; la sacrificielle, où le roi met à mort une victime humaine qui le représente. Le souverain peut alors abandonner son rôle de martyr pour devenir le roi soleil. Si la purification peut être vue comme une expiation, j'ai cependant du mal à concevoir l'autosacrifice comme «l'expulsion du sang porteur d'impureté ». Ce rite est aussi et surtout don de soi comme l'est le sacrifice de l'autre ; ce don sert à payer sa dette auprès des puissances surnaturelles et d'investissement pour leur forcer la main. À côté de la culpabilité qu'ils éprouvaient pour leurs propres fautes, le sacrifiant et l'autosacrifié étaient coupables d'être d'éternels débiteurs. Dans la mythologie, l'autosacrifice est aussi démonstration d'humilité, le contraire de l'orgueil (de vouloir égaler les dieux) qui est la transgression la plus fréquente.

3 L'auteur examine ensuite les transformations de la royauté sacrée pendant la Colonie. Les deux faces, rituelle et sociale, du roi, indissolublement liées avant la Conquête, se séparent avec l'arrivée des Espagnols: la face administrative se tourne vers le conquérant, la face rituelle vers la population indienne. De nouveaux groupes périphériques, les confréries et les desservants d'église apparaissent et se multiplient. Le "système des charges " contemporain est en fait la version moderne d'un système de royauté sacrée. L'auteur s'attache à démontrer que les fonctions "royales " existent toujours dans les communautés indiennes actuelles. Ces fonctions sont : pénitentielles (formant un complexe expiatoire qui comprend jeûne, veille, réclusion, abstinence et bain); rituelles, où la pénitence est suivie du sacrifice (mise à mort d'un animal domestique, communion et dons restreints au banquet); sacerdotales, exécutées par des spécialistes; coercitives (police et justice). Le gouvernant est en outre garant de la prospérité et responsable du malheur collectif. Danièle Dehouve, à l'aide de plusieurs exemples, étudie comment les mêmes fonctions peuvent être attribuées à des postes différents : comisario et xiña chez les Tlapanèques du Guerrero, alcalde civil et alcalde rezador chez les Chuj du Guatemala.

Dans un dernier chapitre, l'auteur démontre comment le groupe central est répliqué dans un grand nombre de groupes périphériques, qui possèdent chacun leur propre personnage central, doté, à petite échelle, des mêmes fonctions « royales ".

5 Le modèle de la royauté sacrée semble donc rendre bien mieux compte de la structure sociale de la Mésoamérique indienne que le « système des charges » des années 1950 et suivantes. Il est tout à fait remarquable qu'un même système, mis en place à l'ère précolombienne, se soit perpétué jusqu'à nos jours après l'effondrement de l'empire aztèque, puis celui de la colonisation espagnole. Comment a-t-il pu se maintenir dans des contextes aussi différents? C'est ce que l'auteur parvient à expliquer de façon convaincante. Sa description de la royauté sacrée chez les Aztèques peut parfaitement s'appliquer à la royauté sacrée des Mayas de la période classique (300-900 de notre ère). Sur les images - que les textes ne contredisent point -, le roi maya fait étalage de sa 
pratique de l'autosacrifice. Il apparaitt comme le grand guerrier et le grand sacrifiant. Son corps et son costume sont des microcosmes : il représente donc l'univers. Il est assimilé au soleil : la carrière royale et le cycle dynastique sont comparés à la trajectoire solaire. Le roi maya est aussi l'incarnation de la société tout entière, garant de sa prospérité et responsable de son malheur. Son intronisation, telle qu'elle est illustrée à Palenque, se déroule comme un rite d'initiation avec descente aux enfers, mort symbolique et renaissance. Il ne fait donc aucun doute que la tradition de la royauté sacrée en Mésoamérique était déjà bien établie dès le début de notre ère. Il est d'ailleurs fort probable que les rois olmèques étaient également sacrés et investis des mêmes fonctions " royales »; dans cette hypothèse, tout porte à croire que la royauté sacrée serait bel et bien un élément constitutif de la tradition culturelle mésoaméricaine.

\section{INDEX}

Index géographique: Mexique

Thèmes : Anthropologie sociale

\section{AUTEURS}

\section{CLAUDE-FRANÇOIS BAUDEZ}

Directeur de recherche honoraire au CNRS 